\title{
Level of tourists' expectation and experience to the heritage sites of Ilocos Sur
}

\author{
Baclig, Elizabeth \\ University of Northern Philippines, Philippines (elizabethbaclig93@gmail.com) \\ Ylagan, Alex \\ Lyceum of the Philippines University - Batangas, Philippines (alexylagan04@gmail.com)
}

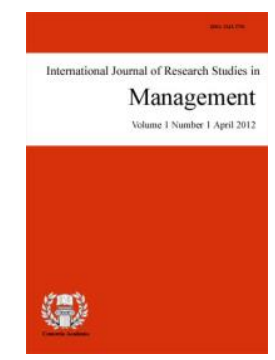

ISSN: $2243-7770$ Online ISSN: 2243-7789

OPEN ACCESS

\section{Abstract}

The study's main goal was to evaluate and explore the level of tourists' expectation and experience of historical sites as a basis for management plan in Ilocos Sur. It presented the profile of the respondents, assessed the tourist expectation in terms of environment, range of attractions, tourism services and transportation, and determine the levels of experience to heritage sites related to learning experience, emotional experience, meaningful experience and enjoyment. Descriptive research and modified questionnaire was utilized to collect data from 416 tourists who visited Ilocos Sur's heritage sites at least once. Frequency and percentage distribution, weighted mean and ranking, and Analysis of Variance were utilized as statistical tools. Based on the result, majority of the respondents belong to generation Z, female, students, visited more than three times, local tourist and travelled with family. Respondents met their expectations as most of the respondents highly experienced in terms of learning experience, emotional experience, meaningful experience, and enjoyment. Respondents achieved greater experience relating to enjoyment. Moreover, there is a considerable disparity in experience levels to heritage sites in terms of enjoyment when grouped to sex and number of times visited. A Management Plan to the Heritage Sites in Ilocos Sur was hereby proposed by the researcher to be used as a guide for future project planning and give tourism stakeholders and Ilocos Sur Provincial Tourism Office insights on how to continuously improve tourism services and promoting the heritage sites.

Keywords: experience, expectations, heritage site or historical site, Ilocos Sur, tourism 


\section{Level of tourists' expectation and experience to the heritage sites of Ilocos Sur}

\section{Introduction}

A trip to a historic landmark is like stepping back in time where and when history teaches the present generation the grandeur of years gone by. These heritage sites are visited by tourists with their expectations that are conceived with the influence of social media, news and travel blogs. With an expectation, tourist believe they know what something will look like or how an experience will go, as well as what they believe the most likely outcome will be. Many tourists have the expectation to indeed have the experience of a lifetime.

There are several variables that influence tourists' expectations, such as the cultural and architectural aspects of the city as well as its cuisine and infrastructure. Visitors are drawn to the site because of these traits, which enhance the whole vacation experience (Universitat Pompeu Fabra - Barcelona, 2019). The study of Kempiak et al., (2017) mentions that visitor experiences are made up of a variety of elements, it is also important to examine characteristics in the heritage environment that influence the tourists' experience and behavior throughout their stay. Innovation is vital for improvement since tourists' needs are continually changing. Technology not only aids in the preservation of historical artifacts, but it may also be used to recreate them and can also be put at the service of heritage to process millions of historical documents, paintings, landscapes, and monuments. This has the potential to transform the tourism sector by offering new experiences at the intersection of the digital and real worlds (Viola, 2019). Understanding the motivations, interests, expectations, and perception of visitors to historical heritage sites is critical to the management of a World Heritage Site (Medina-Viruel et al., 2019). It was shown that tourists' expectations are strongly influenced by their pleasure with their experience, according to a study conducted by Kung (2018).

This study focused on tourists' expectation and experience to heritage sites in Ilocos Sur. The "Heritage Village of the Philippines" is one of the country's most historically significant destinations, combining colorful Ilocano culture with colonial Spanish legacy. The province, well-known for its centuries-old architecture, heritage sites, national shrine, museums, ancestral houses, and cobblestoned streets, is perfect for travelers and history aficionados and will find it enticing. Ilocos Sur is world-famous for not one, but two United Nations Educational, Scientific and Cultural Organization (UNESCO) World Heritage Sites that let tourist travel back in time. A Spanish historic town that has been meticulously conserved, Vigan is a must-see for anybody visiting the Philippines and Nuestra Señora dela Asunción is one the four Baroque Churches of the Philippines.

The recognition of Vigan City as one of the New7Wonders Cities introduced Ilocos Sur to the whole world led to the increasing number of tourists. According to the Provincial Tourism Development and Promotions Office in the latest data, as of 2019, there were 2,395,469 tourist arrivals with day visitors (accommodation establishments and tourist attractions) both domestic and international tourists. This achievement makes this study relevant because there are few studies that have been conducted on tourists' expectation and experience in Ilocos Sur. However, the most important part is to find out if the positive expectation from tourists for their experience is being met. Tourists visit their dream destinations, but the reality of the visit may not always meet their expectations. To sum up, with the recent studies, it has been confirmed that the tourist expectations have a substantial impact on satisfaction with the experience, however there is still a problem in determining if the tourists experience meets their expectations.

In line with this, this research is of great importance as it examined the factors influencing the tourist experience. Better understanding of tourists and their experiences will be a basis in designing management plans and adding innovative components. The Ilocos Sur Provincial Tourist Office and the tourism stakeholders will benefit from this study, for this will serve as a reference for future project planning and give them insights on how to continuously improve tourism services and promoting the heritage sites.

This research evaluated and explored the level of tourists' expectation and experience of historical sites as a basis for management plan in Ilocos Sur. Specifically, this aimed to: provide an overview of the profile of the respondents in terms of: age, sex, occupation, frequency of visit, type of tourist and travel party; asses the 
tourists' expectation to heritage sites in terms of: environment, range of attractions, tourism services and transportation; identify the levels of experience to heritage sites related to: learning experience, emotional experience, meaningful experience and enjoyment; determine the significant difference on the assessment of tourists' expectation and the levels of experience when group according to profile variable; and 5) propose management plan for the province of Ilocos Sur.

\subsection{Management and Innovations to the Heritage Sites}

Heritage tourism has taken on a whole new dimension thanks to the internet. Strategic marketing and consistent management of experiences that are based on facts are necessary to maintain market share. Proper management of heritage sites means making the destination and events attractive activities for all ages. There is a need to appropriately develop sites and learning experiences to accommodate various types of tourists. The study of Shabalala and Simatele (2020) argued in their study that good heritage conservation management techniques, as well as sustainable tourism, necessitate not just a greater understanding of the worth of heritage assets, but also the full engagement and participation of people living near these resources. As a result of their study, Su et al. (2020) suggested that when it comes to attracting tourists, heritage site managers should focus on upgrading the quality of the infrastructure as well as the services provided by nearby hotels, restaurants, and other food and beverage establishments. According to the specific characteristics of World Heritage Sites, managers can utilize social media data to compare and forecast the amount of social media posts regarding World Heritage Sites in the future (Falk \& Hagsten, 2020). In the historical tourism business, immersive technology, such as augmented and virtual reality, has the potential to provide remarkable experiences. By fusing history with cutting-edge technology in immersive settings, the study by Bec et al. (2019) shows that visitors' experiences and subsequent engagement with history can be improved while simultaneously protecting and managing legacy.

\subsection{Tourists' Expectation to Heritage Sites}

Expectations arise from the moment a tourist begins to plan their vacation, and those initial expectations are based on images and information coming from social media and already stored in their memory. When planning a trip, the tourist compares his or her expectations of the destination's cultural and historic quality with what he or she actually experiences when they arrive at the destination. They do this by talking to locals, staying in hotels, visiting monuments, and taking in the sights of the heritage city as a whole (Hernández-Rojas et al., 2021). The findings of Sánchez-Fernández et al. (2020) concluded that exceeding expectations is crucial for customer preference. In the research of Apritado and Borbon (2020) they stated that the vast majority of attraction respondents are repeat visitors. Expectations and experiences at tourist attractions include a well-built setting and friendly locals, a variety of local transit options, and the chance to participate in religious activities.

Environment - Our cultural heritage is an important part of our environment. The quality of the environment has become a concern of tourists as a result of rising environmental consciousness, visitor demand for greater quality, and growing rivalry among destinations. According to Ouattara et al. (2018), the environmental quality is a common concern when making travel-related decisions and it is a competitive factor among tourist destinations. Many studies point to an upsurge in the number of tourists looking for holiday sites in environmentally sensitive areas. Tourism activities, on the other hand, are widely acknowledged to cause enormous environmental damage. The findings of the study of Maxim and Chasovschi (2021), reveal that stakeholders agree to stress the significance of preserving heritage destinations' cultural landscapes, with the majority believing that stricter regulations should be implemented. Wang et al. (2021) investigated the ramifications of various weather conditions and discovered an Inverted-U effect of temperature on tourists' emotional experiences. The study provides deep insights into the impact of the environment on tourism and advances the applications of environmental psychology in tourism settings.

Range of Attractions - Attractions are sites of culture, heritage, natural beauty, or activities that entice visitors to come. It is primarily from the standpoint of the visitor's satisfaction that quality in cultural heritage 
attractions is measured and assessed (Carbone et al., 2020). When tourists evaluated the city's attractions, their judgments of the city's individuality, quality, and/or beauty were all favorably influenced (Shaykh-Baygloo, 2021). Masoud et al. (2018) determined that the concept of intangible cultural heritage is new to domestic tourists. Among the most popular activities for tourists are those that focus on the region's intangible history, such as learning to cook local dishes, making and sampling local sweets, and learning about the region's traditional medicines and healing plants. Providing products and services to visitors constitutes the visitor economy, which comprises both private and governmental sector activity and expenditures (Stainton, 2021).

Tourism Services - Tourism and travel-related services encompass all of the services provided by hotels and restaurants, travel agencies and tour operators, tourist guides, and other associated businesses. The findings of the study of Kabadayi et al. (2019) stated that customers can now enjoy services that were previously inaccessible due to smart services (intelligent, anticipatory, and adaptable data and technology utilization). A visitor survey results in the study of Cudny et al. (2021) revealed that event is a major draw for tourists. According to the comparative analytical results, service providers are aware of some factors that influence visitor expectations, but they might be overlooking two facts that indicate knowledge gaps: how social media affects a place's image and how that image affects what people expect to see there. These two differences show how important it is for service providers to learn more about their customers. (de Lima et al., 2019).

Transportation - Transportation is a significant component of the tourism industry since it connects people to a wide variety of different destinations. There is widespread consensus that when transportation infrastructure improves, more people will come to visit a destination. Martin et al. (2016) came to the conclusion in their study that the mode of transportation used during the visit has a big impact on tourist satisfaction. According to Perea-Medina et al. (2019), promoting public transit over other means of transportation is necessary for the development of a long-term model of tourist mobility, which must be sustainable. The research of Yang et al. (2018) indicates how urban pressure, unregulated tourism and transportation expansion, and other factors contribute to the fragility of World Heritage Sites and the reduction of the ecological value of natural World Heritage Sites.

\subsection{Levels of Experience to Heritage Sites}

A visit to a historic place can be a positive or negative experience depending on the tourist's perspective and the purpose of the visit. Traveling for the purpose of experiencing cultural heritage is a popular leisure activity. In the research of Jimber del Río et al. (2020), they recommended that management of any World Heritage City must be aware of the tourists' experiences at the place in order to encourage them to suggest and return to the location. As a result of the creation of guided tours that provide rewarding experiences at heritage sites, cultural heritage has evolved into a key means of attracting tourists to cities as well as a source of revenue (Crespi-Vallbona, 2020). Managers must therefore examine the guest experience as a whole rather of focusing on just one or two service structures (Oriade \& Schofield, 2019).

Learning Experience - Heritage tourism can be enjoyed by anybody who has a desire to learn. Travelling and exploring heritage sites allowed any tourist to learn the stories about the places, the people and their culture not from the structure of something that was rebuilt, but from the actual traces of what remained. The findings of Qeidari et al. (2021) showed that in addition to raising children's environmental and social awareness, tourism can serve as a beneficial resource for parents and schools interested in incorporating rural tourism into their curriculum as a way to teach their students through hands-on experimentation and observation.

Emotional Experience - Symbolic underpinnings for a sense of belonging are formed on the foundations of cultural heritage, which is why it is an important aspect of national representation. Visiting heritage sites can be an especially emotional experience. The good emotions of travelers who enjoy their trip, relax, learn something new, break away from routine and feel safe are higher. As a result, Domínguez-Quintero et al. (2019) concluded that emotions are a mediating variable in the relationship between experience quality and satisfaction.

74 Consortia Academia Publishing (A Partner of Tourism Educators and Movers of the Philippines) 
Emotionally engaging tourists with a destination or attraction is key to developing an experience. Great heritage attractions evoke emotions, which is a crucial step in the experience creation process (Gursoy et al., 2021). Tourists' emotional experiences (measured by joy, positive surprise, and love) affect their impression of destination image, which determines their satisfaction, according to a study conducted by Prayag et al. (2017).

Meaningful Experience - Travelling in heritage sites and engaging with heritage activities are meaningful experiences because tourists can learn something concrete and new. In order to develop memorable tourism experiences, the avenues employed to engage tourists must fulfill the cultural tourists' need for a deeper cultural experience (Chen \& Rahman, 2018). Many people gained a variety of psychological benefits from their travels, according to the findings of the study of Sie et al. (2021), which lasted long after the trip was over. Memorable encounters and perceived advantages have been discovered to mediate the connections between the motivations or tour choices of senior tourists and their overall happiness in one's life.

Enjoyment - Heritage tourism adds a whole new dimension to travel and may be both enjoyable and enlightening. Travelers' have a burning urge to post about their travels on social media and travel websites was primarily motivated by their perceived enjoyment (Oliveira et al., 2020). Ghorbanzade et al. (2019) introduced in their study that to further understand how tourists enjoy themselves, researchers looked into the notion of expectation-disconfirmation, which states that customers evaluate their actual service provider experience against their expectations. As a result, attraction management should allow for the customization of experiences and think about how minor deviations from the rules can lead to positive experience evaluations. Obviously, this must have a counter-balance maintaining norms for health and safety in the workplace as well as ensuring the heritage site's long-term viability and the enjoyment of other visitors (Melvin et al., 2020).

\section{Method}

Research Design - Descriptive and quantitative methods were used in this study. Consequently, this approach was appropriate for this research because it is primarily concerned to evaluate and explore the tourists' expectation and experience of historical sites as a basis for management and innovation plan in Ilocos Sur. The report of Loeb et al. (2017) indicated that to answer inquiries about the world and/or a phenomenon, descriptive analysis answers who, what, where, when, and how questions. When dealing with quantitative data, both experimental and non-experimental designs can be used. Unlike comparative and correlation designs, which are strictly non-experimental, experimental designs in nature (Siedlecki, 2020).

Participants of the Study - Respondents were both local and foreign tourists, who visited heritage sites in Ilocos Sur at least once and who are technologically literate to answer the questionnaire using the Google Form. The number of respondents was based on the data of tourist arrivals with day visitors (accommodation establishments and tourist attractions) in 2019 as released by the Ilocos Sur Provincial Tourism Development and Promotions Office. Purposive sampling was used by the researcher, in which respondents were believed to be knowledgeable about the subject matter. The researcher utilized a sample of 385 based on the Raosoft Sample Size Calculator considering the total tourist arrival in Ilocos Sur of 2,395,469. The level of confidence is 95 percent, while the margin of error is 5 percent. But more than the sample size of respondents answered the survey questionnaire for there was a total of 416 who responded.

Data Collection Instrument - The questionnaire was adapted and modified based on the study of Apritado. (2019) entitled "Proposed management and innovations to the historical destinations in CALABARZON: inputs from tourists' motives, expectation and experience". It was divided into three sections.: Part I revealed the demographic profile of the respondents in terms age, sex, occupation, frequency of visit, type of tourist and travel party. Part II assessed the tourists' expectation to heritage sites in terms of: environment, range of attractions, tourism services and transportation. Part III identified the levels of experience to heritage sites associated to: learning experience, emotional experience, meaningful experience and enjoyment. The study instrument was validated by a researcher's adviser and a statistician. Prior to distributing the survey to the 
Baclig, E., \& Ylagan, A.

respondents, pilot testing and reliability were carried out, involving 34 people in the pilot testing.

Data Gathering Procedure - A communication letter through messenger or email was sent to the respondents asking for the permission to conduct the study. For the survey questionnaire floating, when permission has been granted, survey questions were then distributed to respondents using a Google form link.

Data Analysis - Following questionnaire validation, the data was encoded, calculated, and analyzed with the Statistical Package for Social Sciences (SPSS). Various statistical analyses, including frequency distribution, percentage distribution, ranking distribution, and weighted mean, were utilized to achieve each of the study's objectives. The Analysis of Variance (ANOVA) method was used to examine whether there was a statistically significant difference between groups based on the profile variables to analyze and explore the level of tourists' anticipation and experience with historical sites in Ilocos Sur.

Ethical Consideration - The study did not include any specific names in order to maintain the survey's confidentiality. The respondents were assured of their anonymity upon deciding whether they wish to participate or abstain. It was made clear that their identity and confidentiality is guaranteed, and results will be utilized only as needed for the study's objectives. The study prioritized research respect and dignity, and full consent from the participant was obtained prior to the study. The researcher ascertained that ethical considerations have been established prior to beginning the study before proceeding. The researcher asked the author for permission to use and modify the adopted questionnaire before distributing it to the participants. Finally, research privacy was protected.

\section{Results and Discussion}

Table 1

Profile of the Respondents

\begin{tabular}{|c|c|c|}
\hline Age & Frequency & Percentage \\
\hline 22 years old and below (Gen $\mathrm{Z})$ & 265 & 63.70 \\
\hline 23-38 years old (Gen $Y)$ & 108 & 26.00 \\
\hline $39-54$ years old $($ Gen $X)$ & 35 & 8.40 \\
\hline 55 years old and above (Baby Boomers) & 8 & 1.90 \\
\hline \multicolumn{3}{|l|}{ 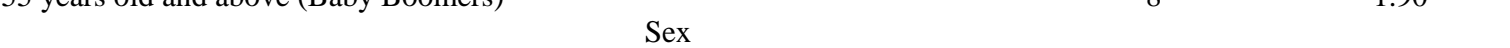 } \\
\hline male & 181 & 43.50 \\
\hline female & 235 & 56.50 \\
\hline \multicolumn{3}{|l|}{ Occupation } \\
\hline student & 264 & 63.50 \\
\hline employee & 84 & 20.20 \\
\hline self-employed & 32 & 7.70 \\
\hline OFW's & 17 & 4.10 \\
\hline others & 19 & 4.60 \\
\hline \multicolumn{3}{|c|}{ Number of Times Visited a Heritage Site in Ilocos Sur } \\
\hline 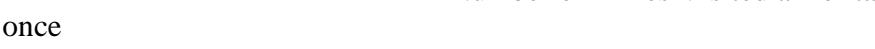 & 100 & 24.00 \\
\hline twice & 33 & 7.90 \\
\hline thrice & 12 & 2.90 \\
\hline more than thrice & 271 & 65.10 \\
\hline \multicolumn{3}{|l|}{ Type of Tourist } \\
\hline local tourist & 382 & 91.80 \\
\hline foreign tourist & 34 & 8.20 \\
\hline \multicolumn{3}{|l|}{ Travel Party } \\
\hline alone & 102 & 24.52 \\
\hline with husband/wife & 26 & 6.25 \\
\hline family & 260 & 62.50 \\
\hline friends & 183 & 43.99 \\
\hline organized group & 53 & 12.74 \\
\hline \multicolumn{3}{|c|}{ Heritage Sites / Historical Sites Visited in Ilocos Sur } \\
\hline Calle Crisologo (Heritage Village), Vigan City & 405 & 97.36 \\
\hline Nuestra Señora de la Asuncion (Sta. Maria Church), Sta Maria & 234 & 56.25 \\
\hline Loom Weaving (Pag-abelan) and Pottery (Pagburnayan), Vigan City & 231 & 55.53 \\
\hline
\end{tabular}

76 Consortia Academia Publishing (A Partner of Tourism Educators and Movers of the Philippines) 


\begin{tabular}{lll}
\hline National Museum Ilocos Regional Complex (Old Provincial Jail), Vigan City & 180 & 43.27 \\
Father Burgos Museum (Family House of Father Jose Burgos), Vigan City & 173 & 41.59 \\
Syquia Mansion, Vigan City & 132 & 31.73 \\
Crisologo Museum (former Congressman Floro Crisologo's house), Vigan City & 184 & 44.23 \\
St. Agustin Parish and Bantay Bell Tower, Bantay & 201 & 48.32 \\
Battle of Bessang Pass Monument, Cervantes & 101 & 24.28 \\
Moro Watch Tower, San Esteban & 96 & 23.08
\end{tabular}

As shown in the table above, majority of respondents are 22 years old or younger (Gen Z) composing 265 or 63.70 percent of the total population followed by 108 or 26 percent participants who are 23-38 years old (Gen Y). This proves that young people make up a significant portion of tourists in cultural heritage destinations. Using technology in the tourism sector to reach a bigger number of tourists while also delivering more information and services, including those tailored to each user's profile, is becoming increasingly popular. Today's most important demographic segment is Generation Z (Truyols, n.d.). 35 or 8.40 percent participants are 39-54 years old (Gen $\mathrm{X}$ ), and finally 8 or 1.90 percent had an age ranging from 55 years old and above (Baby Boomers). From the results above, it can be inferred that the least amount of travel was possible for older people in historical sites. Baby boomers have a diverse set of expectations and actively seek out personalized, realistic, and memorable travel experiences. According to the results of the research undertaken by Wilson et al. (2018), older adults are becoming more likely to participate in more physically active and adventurous activities. Baby boomers are on the lookout for activities that they believe will help them stay young, and it appears that they have discovered them in parks.

Among 416 respondents, in terms of sex, the sample was comprised of 235 or 56.50 percent female and 181 or 43.50 percent male. This implies that there are more women who are engaged into visiting heritage sites. Women tend to be more interested in travelling to these places rather than men. There are an increasing number of women who have successful careers who travel, self-sufficient and have never married. When it comes to family travel and vacations, women are typically the planners. Many women have the opportunity to travel because, in some cases, as they work and save money, they have the opportunity to travel alone or with their female friends. Wang et al. (2017) discovered that when it comes to the influence of perceived quality of the place on visitor satisfaction, female travelers have a stronger influence on visitor satisfaction than male tourists.

In terms of occupation, majority of the participants are student with a total of 264 or 63.50 percent, following employee, which are composed of 84 or 20.20 percent. 32 or 7.70 percent are self-employed. This means that students are frequent travelers. Field trips for educational purposes have resulted in a large number of traveling students who have appeared at historical sites. The researcher agreed with the study carried out by Mindanao et al. (2018) that the vast majority of visitors to heritage destinations are students who are there with a purpose to learn something new. 19 or 4.60 percent and 17 or 4.10 percent are for other occupation and Overseas Filipino Worker respectively. Due to the length of their vacations and the fact that they are usually away for work, Overseas Filipino Worker travel is limited.

In terms of frequency of travelers with regards to the number of times visited a heritage site in Ilocos Sur, majority of the respondents visited more than thrice with 271 or 65.10 percent, followed by visited once with 100 or 24 percent. Ilocos Sur offers quite a spectrum of things tourist can do and places they can visit. Tourist might just even run out of time and revisiting is the only way they can experience more of what Ilocos Sur has to offer. Furthermore, 33 or 7.90 percent of the participants visited twice, and lastly 12 or 2.90 percent did their visit thrice. This implies that the least number of participants already contented exploring Ilocos Sur on their third visit. Returning tourists and visitors talk about their travel and experiences with loved ones and acquaintances and coworkers (Hernández-Rojas et al., 2021). The findings of Chen and Rahman (2018), show that tourists' inclinations to return to and suggest a cultural site are positively influenced by their pleasant tourism experiences.

In terms of type of tourist, most of the respondents are local tourists with 382 or 91.80 percent. This means that locals travel to historical sites to explore and to gain firsthand knowledge of artifacts in the country. There is 
a substantial variance in the percentages of visitors to a tourist site depending on the type of tourist who comes. Local tourists got the most responses because some are on field trips and most are students, while others are adults who want to see historical sites to learn. It can be concluded that local tourists are more expected to visit heritage sites in Ilocos Sur than foreign tourist. The foreign tourist (Indian, Nepali, American, Spanish, Sri Lankan, Canadian, Qataris, New Zealander, Dutch, Nigerian and British) is composed of 34 or 8.20 percent.

For the travel party, majority of the respondents visited heritage sites in Ilocos Sur with family with 260 or 62.50 percent, followed by visited alone with 102 or 24.52 percent. This denotes that provided opportunities, tourists are more likely to have their family as travel party. A family's reliance on children's education has made experiential learning an important motivation for family travel. Parental involvement and parental influence on children's growth may have a greater long-term impact than other types of travel (Yang \& Lau, 2019). 53 or 12.74 percent of the participants visited with organized group, and lastly visited with husband/wife with 26 or 6.25 percent. This could imply that couple prefers a romantic getaway for their travel. As to the top 10 Heritage sites / historical sites visited in Ilocos Sur, it appeared in the table that almost all of the respondents visited Calle Crisologo (Heritage Village), Vigan City with a frequency of 405 or 97.36 percent, followed by Nuestra Señora de la Asuncion (Sta. Maria Church), Sta Maria with a frequency of 234 or 56.25 percent, then Loom Weaving (Pag-abelan) and Pottery (Pagburnayan), Vigan City with a frequency of 231 or 55.53 percent.

As a result of being designated as UNESCO World Heritage Sites in the Philippines, the first and second most visited heritage sites in Ilocos Sur are Vigan City and Nuestra Señora de la Asuncion. It is very worthy to visit Vigan City since of its charm not only because of being declared an internationally recognized historic site but also because of being one of the World's New Seven Wonder Cities. The lowest 3 were Syquia Mansion, Vigan City with a frequency of 132 or 31.73 percent, Battle of Bessang Pass Monument, Cervantes with a frequency of 101 or 24.28 percent and, lastly Moro Watch Tower, San Esteban with a frequency of 96 or 23.08 percent. The last heritage site is not very well known, it is far from the highway and if tourists are coming from the capital of Ilocos Sur which is Vigan City, it will take them around an hour of land travel to reach the municipality of San Esteban, this resulted Moro Watch Tower as the least visited heritage sites in Ilocos Sur.

For any World Heritage City to thrive, its management must be aware of visitors' experiences at the destination, including their expectations for the trip, their expectations for the destination's quality of service, their satisfaction with the destination, and how these factors affect visitor loyalty to the city, because it is critical to get visitors recommending and returning to the destination (Jimber del Río et al., 2020). The results of the study by Castillo-Manzano et al. (2021) shows World Heritage Sites have a favorable effect on the demand for travel both domestically and internationally, with the first World Heritage Sites having a stronger tourism-enhancing effect. On the other hand, result in the research of Canale et al., (2019) suggest that receiving a World Heritage designation, additionally to the province's wealth, environmental practices, and openness to external markets may all influence appeal, supporting the list's importance as a tourism booster beyond cultural protection.

\section{Table 2}

Assessment on the Tourists' Expectation to Heritage Sites in terms of Environment

\begin{tabular}{|c|c|c|c|}
\hline Environment & WM & VI & Rank \\
\hline 1. I expect clean and hygienic environment. & 4.61 & Highly Expected & 3 \\
\hline 2. I expect pleasant weather and climate condition. & 4.36 & Expected & 6.5 \\
\hline 3. I expect old/historic visual appeal. & 4.57 & Highly Expected & 4 \\
\hline 4. I expect modern/visual appeal. & 4.27 & Expected & 10 \\
\hline 5. I expect that several recreation areas are available. & 4.44 & Expected & 5 \\
\hline 6. I expect dense built environment. & 4.33 & Expected & 9 \\
\hline 7. I expect establishments that offers all kinds of delicious local cuisine. & 4.63 & Highly Expected & 2 \\
\hline 8. I expect friendliness and hospitality of the local people. & 4.67 & Highly Expected & 1 \\
\hline 9. I expect that the influx of people will not make me feel crowded. & 4.33 & Expected & 8 \\
\hline 10. I expect clean public toilet in the sites. & 4.36 & Expected & 6.5 \\
\hline Composite Mean & 4.46 & Expected & \\
\hline
\end{tabular}

78 Consortia Academia Publishing (A Partner of Tourism Educators and Movers of the Philippines) 
As seen in Table 2, the composite mean on the Assessment on the Tourists' Expectation to Heritage Sites in terms of Environment is expected with 4.46. The first rank respondents expect friendliness and hospitality of the local people with mean values 4.67; on the second rank, they expect establishments that offers all kinds of delicious local cuisine with mean values 4.63 , and third rank, respondents expect clean and hygienic environment with mean values 4.61 obtained a rating of highly expected respectively.

The friendliness and hospitality of the locals are likely to be the most important factors for visitors. In other words, the social environment must provide the visitors experiences that they will cherish long after they have visited a place. They perceived people in Ilocos Sur to be friendly and hospitable as local hospitality is an important part of the heritage experience for them to feel secure and safe. Local attitudes toward tourists, such as helpfulness, politeness, friendliness, being social, kindness, calmness, willingness to share, hospitability, and level of goodwill, all influence how tourists perceive their experiences (Gursoy, et al., 2021).

Tourists expect that the influx of people will not make me feel crowded and I expect dense built environment (4.33) got the same lowest value, then I expect modern/visual appeal (4.27) ranked the least. People who go to heritage sites really expect old things and learn from the past and look at their value in terms of the present. They don't really expect modern things so this is probably the reason why it got the lowest ranking. Although tourists are expecting old and historic locations, historic structures, and historic items, this implies that some of the tourists who visit heritage sites still expected modern. Visitors' interest in digital heritage interpretation and presentation was reflected in this finding. Visitors are encouraged to interact with digital environments at historical landmarks (Liu, 2020).

Table 3

Assessment on the Tourists' Expectation to Heritage Sites in terms of Range of Attractions

\begin{tabular}{lccc}
\hline \multicolumn{1}{c}{ Range of Attractions } & WM & VI & Rank \\
\hline 1. I expect variety of museums and galleries. & 4.61 & Highly Expected & 7 \\
2. I expect unique history. & 4.73 & Highly Expected & 1 \\
3. I expect variety of historical sites and cultural attractions. & 4.72 & Highly Expected & 2 \\
4. I expect selection of special events and festivals. & 4.52 & Highly Expected & 9 \\
5. I expect unspoiled historical site. & 4.44 & Expected & 10 \\
6. I expect diversity of cultural/historical site. & 4.64 & Highly Expected & 5 \\
7. I expect availability of cultural and other events. & 4.55 & Highly Expected & 8 \\
8. I expect best-preserved heritage sites that would take you back in time. & 4.69 & Highly Expected & 4 \\
9. I expect to be walking along iconic cobblestone streets. & & 4.64 & Highly Expected \\
10. I expect to see marvelous heritage houses. & 4.70 & Highly Expected & 3 \\
& Composite Mean & 4.62 & Highly Expected \\
\hline
\end{tabular}

Legend: 4.50 - 5.00 -Highly Expected; 3.50 - 4.49 -Expected; 2.50 - 3.49 - Moderately Expected; 1.50 - 2.49 -Less Expected; 1.00 1.49 - Not Expected

It can be gleamed from the results that the respondents highly expected range of attractions as revealed by the composite mean of 4.62. The top 3 expectation of the respondents to heritage sites with regards to the range of attractions include the following: unique history having a mean value of 4.73 ; variety of historical sites and cultural attractions having a mean value 4.72; and marvelous heritage houses having a mean value 4.62.

Expecting unique history obtained the highest weighted mean. This could be attributed to the fact that the Vigan City as a lived in museum has well preserved building and other architecture. Also, this is probably because tourists want to learn about the stories of people who lived before them through heritage travel. The traces of what is remained in the heritage and historical sites will allow them to learn about the stories of people who lived before. They expect to learn something unique, concrete, and novel in order to connect with the heritage. According to Chen and Rahman (2018), a deeper experience and greater understanding of the local culture would enhance travelers' memorable tourism experiences. Cultural tourism is memorable when guided tours and other amenities cater to travelers' cultural interests. The study of Kempiak et al. (2017) suggests that visitors are concerned about heritage preservation, at least to some extent. The fact that visitors are interested in 
personal stories indicates that they want to learn about history; additionally, it supports the previous finding, which emphasizes the need and desire for accurate information.

The 3 very least expected items were the following: I expect availability of cultural and other events, I expect selection of special events and festivals and, I expect unspoiled historical site with a value of 4.55, 4.52, and 4.44 respectively. Perhaps they didn't expect much from the unspoiled historical sites because they thought it would be difficult to visit these places. Additionally, tourists may believe that visiting these locations is restricted by a huge array of restrictions. This implies that respondents have different expectations in terms of range of attractions. Tourist expected more on the unique history of the sites and they did not expect much on the preserved structures. They were already expecting a variety of attractions at historical sites, but they were more interested in the places' unique history. Intangible cultural heritage is a concept that many domestic tourists are unfamiliar with. Tourists, on the other hand, are drawn to intangible heritage attractions and activities (Masoud et al., 2018). As the findings in the study of Jimber et al. (2020) show, tourists gain a new perspective on the city's cultural diversity during their stay.

\section{Table 4}

Assessment on the Tourists' Expectation to Heritage Sites in terms of Tourism Services

\begin{tabular}{lccc}
\hline \multicolumn{1}{c}{ Tourism Services } & WM & VI & Rank \\
\hline 1. I expect various tourism information. & 4.55 & Highly Expected & 6 \\
2. I expect convenient opening hours. & 4.47 & Expected & 8 \\
3. I expect availability of tourist attractions signs. & 4.52 & Highly Expected & 7 \\
4. I expect possibilities for shopping. & 4.42 & Expected & 10 \\
5. I expect reasonable price of local services. & 4.47 & Expected & 9 \\
6. I expect various types of local products and services. & 4.61 & Highly Expected & 1 \\
7. I expect personal safety and security. & 4.59 & Highly Expected & 3 \\
8. I expect gastronomic adventures where I can feast on local cuisines. & 4.57 & Highly Expected & 5 \\
9. I expect availability of accommodations to choose from. & 4.60 & Highly Expected & 2 \\
10. I expect accessible tourism services. & 4.58 & Highly Expected & 4 \\
& Composite Mean & 4.54 & Highly Expected \\
\hline
\end{tabular}

Legend: 4.50 - 5.00 -Highly Expected; 3.50 - 4.49 -Expected; 2.50 - 3.49 - Moderately Expected; 1.50 - 2.49 -Less Expected; 1.00 1.49 - Not Expected

Table 4 displays that the composite mean on the Assessment on the Tourists' Expectation to Heritage Sites in terms of Tourism Services is highly expected with 4.54. It can be seen from the table above that the sixth indicator, which is "I expect various types of local products and services", possesses the highest mean rating of 4.61, followed by "I expect availability of accommodations to choose from", held the second highest mean rating by of 4.60, then "I expect personal safety and security" has the third highest mean rating of 4.59 .

This could mean that the respondents "highly expected" various types of local products and services apart from quite an impressive list of heritage sites that will surely interest anyone from adventure seekers to history buffs alike. Knowing that Ilocos is primarily an agricultural and agro-industrial region, tourists expects that the province produces a wide range of products ranging from food products to handicrafts. According to Wang et al (2017), tourism managers must conduct thorough research into the characteristics of tourists to ensure that the destination's goods and services are suitable for them. A city's international shopping destination promotion requires establish coordinated strategies with all local agents, including traders' groups and local institutions (Muro-Rodríguez et al., 2020).

On the other hand, it is clear from the same table that tourists' least expected convenient opening hours and reasonable price of local services with the same mean rating of 4.47, lastly the possibilities for shopping (4.42). This implies that tourists are more interested on enjoying and experiencing the local products and services while they are still there rather than on the opportunity of shopping. Tourists do not expect to do much shopping because most of them are likely city dwellers. They will visit heritage sites to satisfy their curiosity about the area and learn from the old ruins. The study's findings of Menor-Campos et al. (2020) support the notion that the cultural dimension contributes significantly to the satisfaction of the destination. Similarly, increased interest 
leads to significantly different perceptions of the destination's tourist attributes, with cultural resources being valued more highly. Heritage tourism is one of the tourism industry's fastest expanding segments, contributing considerably to local and national economies. Tourists are demanding more memorable and engaging travel experiences in order to expand their cultural horizons and learn new things (Kempiak et al., 2017).

\section{Table 5}

Assessment on the Tourists' Expectation to Heritage Sites in terms of Transportation

\begin{tabular}{lccc}
\hline \multicolumn{1}{c}{ Transportation } & WM & VI & Rank \\
\hline 1. I expect easy to understand and use local transport. & 4.49 & Expected & 5 \\
2. I expect safe transportation to and from places. & 4.61 & Highly Expected & 1 \\
3. I expect convenience of the local transportation services. & 4.53 & Highly Expected & 3 \\
4. I expect good condition of transportation technology. & 4.42 & Expected & 7 \\
5. I expect reasonable prices. & 4.39 & Expected & 8 \\
6. I expect horse-drawn vehicles (calesa). & 4.59 & Highly Expected & 2 \\
7. I expect modes of transportation that allow tourists to roam around freely. & 4.48 & Expected & 6 \\
8. I expect within the ideal attraction's indicators. & 4.52 & Highly Expected & 4 \\
9. I expect very little traffic. & 4.22 & Expected & 10 \\
10. I expect to have enough parking space. & 4.27 & Expected & 9
\end{tabular}

Legend: 4.50 - 5.00 -Highly Expected; 3.50 - 4.49 -Expected; 2.50 - 3.49 - Moderately Expected; 1.50 - 2.49 -Less Expected; 1.00 1.49 - Not Expected

It is clearly visible in Table 5 that the composite mean on the Assessment on the Tourists' Expectation to Heritage Sites in terms of Transportation is expected with 4.45. This table presents the expectation of tourists with regards to transportation. Data shows that safe transportation to and from places has the highest rank with weighted mean of 4.61 followed by horse-drawn vehicles (calesa) with weighted mean of 4.59. On the third rank, convenience of the local transportation services with weighted mean of 4.53 . Tourists expect safe transportation when visiting heritage sites and returning home. Tourists are very concerned about transportation when it comes to ensuring a safe arrival. Access to a safe mode of transportation may play a role within a given segment of tourism, in terms of total satisfaction experienced by visitors. An important part of a tourist's experience is their ability to move around the area easily, and this can be enhanced by providing a variety of transportation options. The research findings of Friman et al. (2020) emphasize the relevance of perceived service quality and travel safety in influencing everyday transportation accessibility. Visitors to a new destination may feel uncomfortable or stressed due to unfamiliar mobility (Kim et al., 2021).

For the low result, reasonable prices with weighted mean of 4.39 , followed by to have enough parking space with weighted mean of 4.27, and finally, very little traffic with weighted mean of 4.22. Perhaps less traffic was expected because tourists believe the province has no traffic and is very different from the big cities. The value of stopped traffic as a tourist destination quality aspect is recognized (Maršanic et al., 2021). According to Martin et al. (2016), visitor needs vary substantially based on their way of access, therefore it's important to know the major features of those that come. Those who travel by private car have significantly different requirements than those who utilize public transportation or who visit the city on a tourist bus with a preplanned excursion. This differentiation is essential for establishing a strategy that is tailored to the needs of each sector.

Table 6

Assessment on Levels of Experience to Heritage Sites in terms of Learning Experience

\begin{tabular}{|c|c|c|c|}
\hline Learning Experience & WM & VI & Rank \\
\hline 1.The information provided about the site is clear. & 4.53 & Highly Experienced & 3 \\
\hline 2. Enriched my understanding about the site. & 4.52 & Highly Experienced & 5 \\
\hline $\begin{array}{l}\text { 3. I discovered historical site not only from history books or } \\
\text { from media and increased my knowledge. }\end{array}$ & 4.59 & Highly Experienced & 2 \\
\hline 4. It was exploratory that enhanced my spirit to learn. & 4.53 & Highly Experienced & 4 \\
\hline 5. I developed a new interest as a result of my visit. & 4.60 & Highly Experienced & 1 \\
\hline Composite Mean & 4.56 & Highly Experienced & \\
\hline
\end{tabular}


As seen in Table 6, the composite mean on the Assessment on Levels of Experience to Heritage Sites in terms of Learning Experience was highly experience with 4.56. Tourists developed a new interest as a result of my visit (4.60) and I discovered historical site not only from history books (4.59) got the first and second highest value. The information provided about the site is clear (4.53) and it was exploratory that enhanced my spirit to learn (4.53) got the same value. This could imply that visitors to Ilocos Sur take away more than just their intended purpose. There are many reasons why people travel, from learning a new language, to experiencing a new culture, to gaining an appreciation for the past. They'll come up with brand-new ideas and methods of accomplishing things. Because of this, they'll be exposed to a wide range of fresh experiences that will broaden their perspective. The knowledge and abilities they've obtained are more meaningful to them since they've really used them instead of just reading about them in a book. As they have already ventured outside their comfort zone, it encourages them to develop new interests. Cultural tourism helps to bring people from different parts of the world together. In today's increasingly polarized world, tourism can also be used to educate, connect, and introduce people to new cultures (Global Heritage Fund, 2019). According to the findings of the study Alexandrakis et al., (2019), cultural heritage sites provide a variety of benefits to society, including both market and non-market benefits.

Then, enriched my understanding about the site (4.52) received the lowest value. This could imply that respondents already enhanced their knowledge and fully understand about the heritage sites when they visited the place since majority of the respondents visited Ilocos Sur more than three times. A UNESCO World Heritage Site is something that everyone, from travelers to adventurers to tourists, has heard of. They're usually referred to as "must-visit" destinations because they're so beautiful and people want to learn more about them out of curiosity. Idilfitri (2016) concluded in her study that cultural heritage benefits society greatly. It helps the current generation learn from previous generations' successes and mistakes to improve.

\section{Table 7}

Assessment on Levels of Experience to Heritage Sites in terms of Emotional Experience

\begin{tabular}{|c|c|c|c|}
\hline Emotional Experience & WM & VI & $\mathrm{R}$ \\
\hline $\begin{array}{l}\text { 1.The historical site enabled me to reminisce about my past and experience a part of my own } \\
\text { heritage. }\end{array}$ & 4.58 & $\mathrm{HE}$ & 2 \\
\hline $\begin{array}{l}\text { 2. I was overwhelmed with the aesthetic / beauty aspect of the historical site and attracted with the } \\
\text { originality of facilities. }\end{array}$ & 4.67 & $\mathrm{HE}$ & 1 \\
\hline 3. I felt connected with the historical site and wants to have a hobby to collect historical souvenirs. & 4.55 & $\mathrm{HE}$ & 4 \\
\hline 4. I felt emotionally involved with the heritage site and its feature. & 4.50 & $\mathrm{E}$ & 5 \\
\hline 5. I was completely immersed in the heritage site. & 4.57 & $\mathrm{HE}$ & 3 \\
\hline Composite Mean & 4.57 & $\mathrm{HE}$ & \\
\hline
\end{tabular}

Legend: 4.50 - 5.00 -Highly Experienced (HE); 3.50 - 4.44- Experienced (E); 2.50 - 3.49 - Moderately Experienced (ME); 1.50 2.49-Less Experienced (LE); 1.00 - 1.49 - Not Experienced at All (NE)

Table 7 reflects the composite mean on the Assessment on Levels of Experience to Heritage Sites in terms of Emotional Experience, highly experienced at 4.57. The top 3 indicators experienced by the respondents to heritage sites with regards to the emotional experience include the following: I was overwhelmed with the aesthetic / beauty aspect of the historical site and attracted with the originality of facilities having a mean value of 4.67; the historical site enabled me to reminisce about my past and experience a part of my own heritage having a mean value 4.58; and I was completely immersed in the heritage site having a mean value 4.57. The results imply that the aesthetic beauty of Ilocos Sur, a region steeped in Ilocano culture and colonial Spanish heritage, made the respondents speechless. Many tourists are not first-time visitors to Ilocos Sur, they have preconceived notions about the region, but they are surprised to discover new attractions when they return. The concept of natural beauty as an aesthetic phrase including the landscape's natural and cultural heritage. A suitably educated person can also perform an artistic interpretation of the natural beauty of the landscape, which can be used to decide on the "national significance" of a particular geographic area (Jenkins, 2020).

The two objects with the least amount of experience in which I felt connected with the historical site and 
want, to have a hobby to collect historical souvenirs and I felt emotionally involved with the heritage site and its feature with a value of 4.55 , and 4.50 respectively. This is the least experienced indicator, possibly because majority of respondents are students. They visit heritage sites as part of an educational field trip or because other tourists are simply interested in sightseeing and visiting the places to make memories They are not particularly interested in having a hobby of collecting items in the places they visit. Emotional attachment to the area or appreciation and respect for any cultural legacy acknowledged as a source of pride to any linked community may be a factor in some people's decision to visit the location (Idilfitri, 2016). In light of this discovery and the fact that emotions have a direct and beneficial impact on contentment, Domínguez-Quintero et al. (2019) concluded that for every degree of authenticity and happiness, emotions operate as a mediating variable.

\section{Table 8}

Assessment on Levels of Experience to Heritage Sites in terms of Meaningful Experience

\begin{tabular}{|c|c|c|c|}
\hline Meaningful Experience & WM & VI & Rank \\
\hline 1. I was able to reflect on the significance of the heritage site and their meaning. & 4.61 & $\mathrm{HE}$ & 3 \\
\hline 2. It gave me a sense of wonder and fascination about the heritage site. & 4.60 & $\mathrm{HE}$ & 4 \\
\hline 3. I was still interested to know more about the heritage site and plan to visit again in the future. & 4.65 & $\mathrm{HE}$ & 1 \\
\hline 4. Seeing the real historical values was the most satisfying aspect of my visit. & 4.64 & $\mathrm{HE}$ & 2 \\
\hline 5. I learned something about myself from this tourism experience. & 4.58 & $\mathrm{HE}$ & 5 \\
\hline Composite Mean & 4.62 & $\mathrm{HE}$ & \\
\hline
\end{tabular}

Legend: 4.50 - 5.00 -Highly Experienced (HE); 3.50 - 4.44- Experienced (E); 2.50 - 3.49 - Moderately Experienced (ME); 1.50 2.49 -Less Experienced (LE); 1.00 - 1.49 - Not Experienced at All (NE)

As seen in the Table 8, the composite mean on the Assessment on Levels of Experience to Heritage Sites in terms of Meaningful Experience was highly experienced with 4.62. It can be seen from the table above that the third item, which is "I was still interested to know more about the heritage site and plan to visit again in the future", has the greatest average rating of 4.65, and is followed by "seeing the real historical values was the most satisfying aspect of my visit", possesses the second highest average rating of 4.64, then "I was able to reflect on the significance of the heritage site and their meaning" has the third highest mean rating of 4.61. This could mean that the respondents are willing to go back, explore and create more memories and meaningful experiences. Perhaps it's also because they'd like to return with someone else. They may wish to return with family members, relatives, spouses, or friends. Travel provides an opportunity for people to connect and bond with one another. It may even facilitate the development of happier relationships by allowing them to share their travel experiences. Zhang et al. (2018) highlighted that the memorable tourism experiences influence the likelihood of returning to a place. Similarly, the study of Kung (2018), he pointed out that the intention of returning to a destination has a substantial influence on the outcome level of satisfaction of tourists.

It is clear from the same table that the tourists' least experienced having a sense of wonder and fascination about the heritage site with the mean rating of 4.60 and learning something about myself from this tourism experience with the mean rating of 4.58. This could imply that for some of the respondents, leaving the comforts of home provides them with the chance to ponder their past lives and have a look at the necessary space and time to let their thoughts to float away. Only a few of them change their lives because of the experience, gaining insights into who they truly are, and better understanding themselves with a new perspective on what they want out of life. The findings of Domínguez-Quintero et al. (2019) support the significance of concepts like the quality of the cultural experience, as well as the emotions that are felt throughout a visit. An authentic, enjoyable, and high-quality experience for tourists should be offered at a destination's cultural tourism attractions which will lead to tourist satisfaction.

As seen from the results, the respondents highly experienced enjoyment as revealed by the composite mean of 4.64. This table presents the experience of tourists with regards to enjoyment. Data shows that tourists really love their experience at the heritage site, and it was found truly inspiring, the highest rank with weighted mean of 4.69 , followed by being thrilled and enjoyed about having a new experience in the heritage sites as it seems that they travelled a hundred years back with weighted mean of 4.67. On the third rank, respondents found exciting 
Baclig, E., \& Ylagan, A.

experience and they felt detached from the outside world while visiting the heritage site with weighted mean of 4.66. This suggests that the respondents had a great time in the province. It demonstrates that they value their experiences in which they were able to immerse themselves in local cultures and secure environments. Tourism in Ilocos Sur is rich in terms of experiences and activities that tourists will love. The findings of Filep and Matteucci (2020) concluded that love is a tourist motivator because it parallels well-established tourist incentives like social contact, kinship, and the strengthening of interpersonal relationships. The powerful human emotion of love can be used to interpret satisfying on-site tourist experiences and post-hoc tourist satisfaction. The reputation of a tourist site has the potential to influence tourist enjoyment, then memorability, and lastly consumer behavior, indicating that both tourist enjoyment and memorability are critical in increasing consumer behavior (Wang et al., 2021).

\section{Table 9}

Assessment on Levels of Experience to Heritage Sites in terms of Enjoyment

\begin{tabular}{|c|c|c|c|}
\hline Enjoyment & WM & VI & $\mathrm{R}$ \\
\hline $\begin{array}{l}\text { 1. I was thrilled and enjoyed about having a new experience in the heritage sites as it seems that I } \\
\text { travelled a hundred years back. }\end{array}$ & 4.67 & HE & 2 \\
\hline 2. I indulged in the activities with so much fun and to be physically refreshed during my visit. & 4.59 & HE & 5 \\
\hline 3. I really love my experience at the heritage site, and it was truly inspiring. & 4.69 & $\mathrm{HE}$ & 1 \\
\hline 4. My visit to historical site aroused my curiosity and interest. & 4.60 & $\mathrm{HE}$ & 4 \\
\hline $\begin{array}{l}\text { 5. It was an exciting experience and I felt detached from the outside world while visiting the } \\
\text { heritage site. }\end{array}$ & 4.66 & $\mathrm{HE}$ & 3 \\
\hline
\end{tabular}
Legend: 4.50 - 5.00 -Highly Experienced (HE); 3.50 - 4.44- Experienced (E); 2.50 - 3.49 - Moderately Experienced (ME); 1.50 2.49 -Less Experienced (LE); 1.00 - 1.49 - Not Experienced at All (NE)

For the low result, visiting historical site aroused tourists' curiosity and interest with weighted mean of 4.60 and they indulged in the activities with so much fun and to be physically refreshed during my visit with weighted mean of 4.59. Student visitors to the historical attraction for educational purposes account for the vast majority of those who answered the questionnaire. For this reason, the mean score for this factor is the lowest. The respondents did not get to do much of what they wanted because they were learning at heritage sites. They travel to a location that has something unique to teach and immerse themselves in order to have the best learning experience. The findings of Fromel et al. (2020) demonstrate the current state and tracking changes in students' chosen and engaged physical activities makes it easier to predict future interests for tourism consumers in schools, which is beneficial for tourism marketers. Refreshed implies that your energy has been replenished and traveling to a new location accomplishes exactly that.

\section{Table 10}

Differences in assessment on the tourists' expectation and experience when grouped to profile variables

\begin{tabular}{|c|c|c|c|}
\hline Age & $\mathrm{U} / \lambda 2 \mathrm{c}$ & p-value & Interpretation \\
\hline \multicolumn{4}{|l|}{ Tourists' Expectation } \\
\hline Environment & 1.31 & 0.73 & Not Significant \\
\hline Range of Attractions & 5.81 & 0.12 & Not Significant \\
\hline Tourism Services & 1.15 & 0.77 & Not Significant \\
\hline Transportation & 0.65 & 0.89 & Not Significant \\
\hline \multicolumn{4}{|l|}{ Levels of Experience } \\
\hline Learning Experience & 1.01 & 0.80 & Not Significant \\
\hline Emotional Experience & 2.17 & 0.54 & Not Significant \\
\hline Meaningful Experience & 4.00 & 0.26 & Not Significant \\
\hline Enjoyment & 1.94 & 0.59 & Not Significant \\
\hline \multicolumn{4}{|l|}{ Sex } \\
\hline \multicolumn{4}{|l|}{ Tourists' Expectation } \\
\hline Environment & 20625.00 & 0.59 & Not Significant \\
\hline Range of Attractions & 19922.50 & 0.26 & Not Significant \\
\hline Tourism Services & 19297.00 & 0.10 & Not Significant \\
\hline Transportation & 20236.00 & 0.39 & Not Significant \\
\hline \multicolumn{4}{|l|}{ Levels of Experience } \\
\hline Learning Experience & 19081.50 & 0.06 & Not Significant \\
\hline Emotional Experience & 19223.00 & 0.08 & Not Significant \\
\hline Meaningful Experience & 19584.50 & 0.14 & Not Significant \\
\hline
\end{tabular}


Level of tourists' expectation and experience to the heritage sites of Ilocos Sur

\begin{tabular}{|c|c|c|c|}
\hline Enjoyment & 18778.50 & 0.03 & Significant \\
\hline \multicolumn{4}{|l|}{ Occupation } \\
\hline \multicolumn{4}{|l|}{ Tourists' Expectation } \\
\hline Environment & 2.17 & 0.70 & Not Significant \\
\hline Range of Attractions & 5.28 & 0.26 & Not Significant \\
\hline Tourism Services & 1.98 & 0.74 & Not Significant \\
\hline Transportation & 1.15 & 0.89 & Not Significant \\
\hline \multicolumn{4}{|l|}{ Levels of Experience } \\
\hline Learning Experience & 3.25 & 0.52 & Not Significant \\
\hline Emotional Experience & 5.10 & 0.28 & Not Significant \\
\hline Meaningful Experience & 3.71 & 0.45 & Not Significant \\
\hline Enjoyment & 2.61 & 0.62 & Not Significant \\
\hline \multicolumn{4}{|l|}{ Tourists' Expectation } \\
\hline Environment & 0.89 & 0.83 & Not Significant \\
\hline Range of Attractions & 0.15 & 0.98 & Not Significant \\
\hline Tourism Services & 1.73 & 0.63 & Not Significant \\
\hline Transportation & 7.23 & 0.07 & Not Significant \\
\hline \multicolumn{4}{|l|}{ Levels of Experience } \\
\hline Learning Experience & 3.66 & 0.30 & Not Significant \\
\hline Emotional Experience & 0.84 & 0.84 & Not Significant \\
\hline Meaningful Experience & 3.32 & 0.34 & Not Significant \\
\hline Enjoyment & 8.45 & 0.04 & Significant \\
\hline \multicolumn{4}{|l|}{ Type of Tourist } \\
\hline \multicolumn{4}{|l|}{ Tourists' Expectation } \\
\hline Environment & 5743.50 & 0.26 & Not Significant \\
\hline Range of Attractions & 5968.50 & 0.42 & Not Significant \\
\hline Tourism Services & 6166.50 & 0.62 & Not Significant \\
\hline Transportation & 6454.50 & 0.95 & Not Significant \\
\hline \multicolumn{4}{|l|}{ Levels of Experience } \\
\hline Learning Experience & 6047.00 & 0.49 & Not Significant \\
\hline Emotional Experience & 5733.50 & 0.24 & Not Significant \\
\hline Meaningful Experience & 5950.50 & 0.39 & Not Significant \\
\hline Enjoyment & 5530.50 & 0.12 & Not Significant \\
\hline
\end{tabular}

Legend: Significant at p-value $<0.05$

Significant differences are not observed in assessment on the tourists' expectation in terms of environment, range of attractions, tourism services and transportation when grouped to age, sex, occupation, number of times visited the heritage sites and type of tourist since the $p$ values that were obtained are larger than the 0.05 criterion of significance. Thus, evaluation on the tourists' expectation in terms of environment, range of attractions, tourism services and transportation does not differ when grouped to age, sex, occupation, number of times visited the heritage sites and type of tourist.

Additionally, there is no apparent variation in the way heritage sites are assessed based on the level of learning experience, emotional experience and meaningful experience when grouped to age, sex, occupation, number of times visited the heritage sites and type of tourist since the computed $\mathrm{p}$ values are greater than 0.05 level of significance. Therefore, assessment in levels of experience to heritage sites in terms of learning experience, emotional experience and meaningful experience does not vary when grouped to age, sex, occupation, number of times visited the heritage sites and type of tourist. Moreover, since the computed $\mathrm{p}$ values are less than 0.05 threshold of significance, there is a significant difference in appraisal of levels of experience to heritage places in terms of enjoyment. This means that pleasure of heritage sites varies by sex and frequency of visits. Female respondents who had already visited heritage sites reported to have higher degrees of enjoyment.

Under Levels of Experience, there was a significant difference in sex enjoyment ( $\mathrm{p}=0.03)$. This means that male and female responses differ significantly, with females scoring significantly higher than males on the scale. There was a significant difference in enjoyment $(\mathrm{p}=0.04)$ between the Levels of Experience and the Number of Times Visited a Heritage Site in Ilocos Sur. There is a considerable difference between the responses, with first-time visitors rating the heritage sites higher than repeat visitors.

Based from the result under the Levels of Experience, the variable enjoyment has a significant difference maybe because the tourist has differing perspectives on the activities and memorable experiences they had during their visit, which influences how much fun they had. The number of activities they participate in and the number of heritage sites they visit determine how tourists rate their enjoyment during their visit. In addition, the number of times they visited the location has an impact on their perception because it may alter their 
expectations and satisfactions. The variety of attractions available to them, as well as the activities in which they engage more frequently, influenced their experience and resulted in a significant difference in enjoyment. Female and male perceptions of the level of enjoyment they will experience when visiting a heritage site are quite different. Perhaps this is because each person has a unique set of interests when it comes to the activities and attractions they will see.

Similar to the study of Mindanao et al. (2020), females and students account for the vast majority of visitors to heritage sites. When it comes to market segmentation, gender is one of the most important factors to consider in the service industry in general and in the tourism industry in particular. For female travelers, perceived destination quality influences word of mouth more than for male tourists. This reflects the fact that women value emotional and perceived quality more than men (Wang et al., 2017). Furthermore, Mitas and Bastiaansen (2018) discussed in their research that novelty is vital to tourists' enjoyment. A tourism experience increases an individual's daily variation in positive emotion levels, which is partly explained by daily variation in novelty, also higher on tourism days.

\section{Conclusion and Recommendation}

The expectation of the tourists who visited the Ilocos Sur Heritage Sites have been highly experienced. Majority of the respondents who visited Ilocos Sur Heritage Sites belongs to generation Z, female, commonly students, have visited more than three times, local tourist and travelled with family. Vigan City's Calle Crisologo (Heritage Village) was the most popular of the province heritage attractions. As to the Tourists' Expectation to Heritage Sites, most of the respondents have high expectation on the range of attractions. The study showed that the tourists to heritage sites highly expected friendliness and hospitality of the people and culture of the region, as well as the diverse range of local goods and services and the ease with which they may be accessed. With regards to the Levels of Experience to Heritage Sites, the respondents met their expectations as most of the respondents highly experienced in terms of learning experience, emotional experience, meaningful experience, and enjoyment. Respondents achieved greater experience relating to enjoyment. Lastly, because of their visit, they developed a new interest, overwhelmed with the aesthetic / beauty aspect of the historical site and attracted with the originality of facilities, still interested to know more about the heritage site and plan to visit again in the future, and really love their experience at the heritage site and it was truly inspiring. There is significant difference in assessment in levels of experience to heritage sites in terms of enjoyment when grouped to sex and number of times visited the heritage sites. It was found out that levels of experience to heritage sites in terms of enjoyment differs when grouped to sex and number of times visited the heritage sites. Respondents who were female and visited the heritage sites once had higher assessment in levels of experience to heritage sites in terms of enjoyment.

Since the expectation of the tourists who visited the heritage sites of Ilocos Sur have been highly experienced, it is highly recommended that the tourism office may highlight beautiful destinations, heritage/historical sites, attractions and as well as the must-try adventure activities on their Sure Ilocos Sur Facebook account by posting photos, directions, and a list of things to do in Ilocos Sur. This is to entice people of all ages and to exceed their expectations in terms of the experiences they will get.

The government may develop parking spaces to heritage zones and other connecting streets to have a secure, free, and smooth movement of tourist especially in the most visited/frequented sites in order to avoid traffic. Moreover, to invest in the acquisition of a tourist bus to transport visitors to other heritage sites in secluded and remote location to attract and provide quality tourist experience.

Tourism officials may invest in new technology and hire professionals who are experts in heritage sites conservation and giving new visual appeal without sacrificing their historical/cultural value. As well as to build Visitor Information Center and Photo Zones to cater to new tourist trends and combine culture with modern technologies like investing in augmented reality (AR). To put it in simple way, smartphone AR apps react to 
environmental triggers and take action. If tourists activated the phone's GPS and camera, the AR app detects their location and responds with content such as sounds, displays, and messages. The app immerses visitors in the past as they move around the site adding to their excitement and better learning experiences.

For more enjoyable experiences, management may improve existing tourist activities for all ages and boost enjoyment by providing additional recreational activities. Increase marketing promotions such as creating readable infographics materials through social media, vlogs and brochures. Also, develop thoughtful and well-designed signage programs, as well as captivating interpretive signs for motorists to provide a consistent message available to tourist. The Provincial Tourism Office may consider sharing the proposed management plan to the municipal tourism offices in order to generate more income but also to improve existing local tourist spots and heritage sites. Also, to enhance the social skills of the Local Government Units residents. Collaboration between the different Local Government Units, Department of Tourism and other National and Local Agencies involved in the preservation and promotion of heritage sites. Further researches on the area of heritage conservation and continuing improvement on the level of tourist satisfaction in visiting heritage sites, effect of Covid-19 in the heritage sites in Ilocos Sur as well as analysis of cost and benefits of heritage attractions may be conducted.

\section{References:}

Alexandrakis, G., Manasakis, C., \& Kampanis, N. A. (2019). Economic and societal impacts on cultural heritage sites, resulting from natural effects and climate change. Heritage, 2(1), 279-305. https://doi.org/10.3390/heritage2010019

Apritado, J. M. (2019). Proposed management and innovations to the historical destinations in CALABARZON: inputs from tourists' motives, expectation and experience. Asia Pacific Journal of Academic Research in Business Administration, 5(1), 22-30.

Apritado, J. M., \& Borbon, N. M. D. (2020). Expectations and experiences of tourists on attractions in Batangas Province. International Journal of Research Studies in Education, 10(1), 13-22. https://doi.org/10.5861/ijrse.2020.5918

Bec, A., Moyle, B., Timms, K., Schaffer, V., Skavronskaya, L., \& Little, C. (2019). Management of immersive heritage tourism experiencs: A conceptual model. Tourism Management, 72, 117-120. https://doi.org/10.1016/j.tourman.2018.10.033

Canale, Rosaria Rita; De Simone, Elina; Di Maio, Amedeo; Parenti, Benedetta (2019). UNESCO World Heritage sites and tourism attractiveness: The case of Italian provinces. Land Use Policy, 85, 114-120. https://doi.org/10.1016/j.landusepol.2019.03.037

Carbone, F., Oosterbeek, L., Costa, C. \& Ferreira, A. M. (2020). Extending and adapting the concept of quality management for museums and cultural heritage attractions: a comparative study of European cultural heritage manager's perceptions. Tourism Management Perspective, 35, 100698. https://doi.org/10.1016/j.tmp.2020.100698

Castillo-Manzano, J. I., Castro-Nuño, M., Lopez-Valpuesta, L., \& Zarzoso, Á. (2021). Assessing the tourism attractiveness of World Heritage Sites: The case of Spain. Journal of Cultural Heritage, 48, 305-311. https://doi.org/10.1016/j.culher.2020.12.005

Chen, H., \& Rahman, I. (2018). Cultural tourism: An analysis of engagement, cultural contact, memorable tourism experience and destination loyalty. Tourism Management Perspectives, 26, 153-163 https://doi.org/10.1016/j.tmp.2017.10.006

Crespi-Vallbona, M. (2020). Satisfying experiences: guided tours at cultural heritage sites. Journal of Heritage Tourism, 1-17. https://doi.org/10.1080/1743873x.2020.1771345

Cudny, W., Jolliffe, L., \& Guz, A. (2021). Heritage event as tourist attraction: the case of Dymarki Swietokrzyskie, Poland. GeoJournal. https://doi.org/10.1007/s10708-021-10407-4

de Lima, Mariana Marques; Mainardes, Emerson Wagner; Rodrigues, Ricardo Gouveia (2019). Tourist expectations and perception of service providers: A Brazilian perspective. Service Business. 
Baclig, E., \& Ylagan, A.

https://doi.org/10.1007/s11628-019-00406-4

Domínguez-Quintero, A. M., González-Rodríguez, M. R., \& Roldán, J. L. (2019). The role of authenticity, experience quality, emotions, and satisfaction in a cultural heritage destination. Journal of Heritage Tourism, 1-15. https://doi.org/10.1080/1743873x.2018.1554666

Falk, M. T., \& Hagsten, E. (2020). Visitor flows to world heritage sites in the era of Instagram. Journal of Sustainable Tourism, 29(10), 1547-1564. https://doi.org/10.1080/09669582.2020.1858305

Filep, S., \& Matteucci, X. (2020). Love in tourist motivation and satisfaction. Journal of Hospitality \& Tourism Research, 109634802092707. https://doi.org/10.1177/1096348020927072

Friman, M., Lättman, K., \& Olsson, L. E. (2020). Public transport quality, safety, and perceived accessibility. Sustainability, 12(9), 3563. https://doi.org/10.3390/su12093563

Fromel, K., Kudlacek, M., \& Groffik, D. (2020). Tourism and physical activity preferences: Development and sustainability strategy. Sustainability, 12(21), 8824. https://doi.org/10.3390/su12218824

Ghorbanzade, D., Mehrani, H., \& Rahehagh, A. (2019). The effect of experience quality on behavioral intentions of domestic tourists in visiting water parks. Cogent Business \& Management, 6(1). https://doi.org/10.1080/23311975.2019.1580843

Global Heritage Fund. (2019, September 27). Why we all need to travel with purpose. https://globalheritagefund.org/2019/09/27/why-we-all-need-to-travel-with-purpose/

Gursoy, D., Akova, O., \& Atsı, O. (2021). Understanding the heritage experience: a content analysis of online reviews of world heritage sites in Istanbul. Journal of Tourism and Cultural Change, 1-24. https://doi.org/10.1080/14766825.2021.1937193

Hernández-Rojas, R. D., del Río, J.A.J., Fernández, A. I. et al. (2021). The cultural and heritage tourist, SEM analysis: the case of The Citadel of the Catholic King. Herit Sci, 9, 52. https://doi.org/10.1186/s40494-021-00525-0

Idilfitri S. (2016) Understanding the significance of cultural attribution. Anthropology, 4, 163. https://doi.org/10.4172/2332-0915.1000163

Jenkins, V. (2020). In defence of natural beauty: aesthetic obligation and the law on the designation of protected landscapes in England and Wales. Environmental Law Review, 22(1), 7-24. https://doi.org/10.1177/1461452919900345

Jimber del Río, J. A., Hernández-Rojas, R. D., Vergara-Romero, A., \& Dancausa Millán, M. G. D. (2020). Loyalty in heritage tourism: the case of Córdoba and its four world heritage sites. International Journal of Environmental Research and Public Health, 17(23), 8950. https://doi.org/10.3390/ijerph17238950

Kabadayi, S., Ali, F., Choi, H., Joosten, H., \& Lu, C. (2019). Smart service experience in hospitality and tourism services. Journal of Service Management. https://doi.org/10.1108/josm-11-2018-0377

Kempiak, J., Hollywood, L., Bolan, P., \& McMahon-Beattie, U. (2017). The heritage tourist: an understanding of the visitor experience at heritage attractions. International Journal of Heritage Studies, 23(4), 375-392. https://doi.org/10.1080/13527258.2016.1277776

Kim, H., Koo, C., \& Chung, N. (2021). The role of mobility apps in memorable tourism experiences of Korean tourists: Stress-coping theory perspective. Journal of Hospitality and Tourism Management, 49, 548-557. https://doi.org/10.1016/j.jhtm.2021.11.003

Kung, R.H. (2018). A study of the tourists' expectation, satisfaction and revisiting intention in the Neiwan, Hsinchu. International Journal of New Developments in Engineering and Society, 2(1), 43-49.

Liu, Y. Evaluating visitor experience of digital interpretation and presentation technologies at cultural heritage sites: a case study of the old town, Zuoying. Built Heritage 4, 14 (2020).

https://doi.org/10.1186/s43238-020-00016-4

Loeb, S., Dynarski, S., McFarland, D., Morris, P., Reardon, S., \& Reber, S. (2017). Descriptive analysis in education: A guide for researchers. (NCEE 2017-4023). Washington, DC: U.S. Department of Education, Institute of Education Sciences, National Center for Education Evaluation and Regional Assistance.

Maršanic, R., Mrnjavac, E., Pupavac, D., \& Krpan, L. (2021). Stationary traffic as a factor of tourist destination quality and sustainability. Sustainability, 13(7), 3965. https://doi.org/10.3390/su13073965

88 Consortia Academia Publishing (A Partner of Tourism Educators and Movers of the Philippines) 
Level of tourists' expectation and experience to the heritage sites of Ilocos Sur

Martin, J. C., Marrero-Rodríguez, J. R., Moreira, P., Román, C., \& Santana, A. (2016). How Access Transport Mode to a World Heritage City Affects Visitors' Experienced Quality. Tourism Economics, 22(2), 207-226. https://doi.org/10.5367/te.2016.0550

Masoud, H., Mortazavi, M., \& Torabi Farsani, N. (2018). A study on tourists' tendency towards intangible cultural heritage as an attraction (case study: Isfahan, Iran). City, Culture and Society. https://doi.org/10.1016/j.ccs.2018.11.001

Maxim, C., \& Chasovschi, C. E. (2021). Cultural landscape changes in the built environment at World Heritage Sites: Lessons from Bukovina, Romania. Journal of Destination Marketing \& Management, 20, 100583. https://doi.org/10.1016/j.jdmm.2021.100583

Medina-Viruel, M. J., López-Guzmán, T., Pérez Gálvez, J. C., \& Jara-Alba, C. (2019). Emotional perception and tourist satisfaction in world heritage cities: the renaissance monumental site of úbeda and baeza, Spain. Journal of Outdoor Recreation and Tourism, 27, 100226. https://doi.org/10.1016/j.jort.2019.100226

Melvin, J., Winklhofer, H., \& McCabe, S. (2020). Creating joint experiences - families engaging with a heritage site. Tourism Management, 78, 104038. https://doi.org/10.1016/j.tourman.2019.104038

Menor-Campos, A., Pérez-Gálvez, J. C., Hidalgo-Fernández, A., \& López-Guzmán, T. (2020). Foreign tourists in world heritage sites: a motivation-based segmentation. Sustainability, 12(8), 3263. https://doi.org/10.3390/su12083263

Mindanao, R. M. D., Abarintos, R. C. M., Briones, R.C., Espiritu, J.F., Vergara, P.M.P. \& Apritado, J.M. (2020). Factors influencing tourist attendance at historical attractions. Journal of Tourism and Hospitality Research, 17(1) https://research.lpubatangas.edu.ph/wp-content/uploads/2020/06/JTHR-2020-006.pdf

Mitas, O., \& Bastiaansen, M. (2018). Novelty: a mechanism of tourists' enjoyment. Annals of Tourism Research, 72, 98-108. https://doi.org/10.1016/j.annals.2018.07.002

Muro-Rodríguez, A. I., Pérez-Jiménez, I. R., \& Sánchez-Araque, J. A. (2020). Impact of shopping tourism for the retail trade as a strategy for the local development of cities. Frontiers in Psychology, 11. https://doi.org/10.3389/fpsyg.2020.00067

Oliveira, T., Araujo, B., \& Tam, C. (2020). Why do people share their travel experiences on social media? Tourism Management, 78, 104041. https://doi.org/10.1016/j.tourman.2019.104041

Oriade, A., \& Schofield, P. (2019). An examination of the role of service quality and perceived value in visitor attraction experience. Journal of Destination Marketing \& Management, 11, 1-9. https://doi.org/10.1016/j.jdmm.2018.10.002

Ouattara, B., Pérez-Barahona, A., \& Strobl, E. (2018). Dynamic implications of tourism and environmental quality. Journal of Public Economic Theory. https://doi.org/10.1111/jpet.12330

Perea-Medina, B., Rosa-Jiménez, C., \& Andrade, M. J. (2019). Potential of public transport in regionalisation of main cruise destinations in Mediterranean. Tourism Management, 74, 382-391. https://doi.org/10.1016/j.tourman.2019.04.016

Prayag, G., Hosany, S., Muskat, B., \& Del Chiappa, G. (2017). Understanding the relationships between tourists' emotional experiences, perceived overall image, satisfaction, and intention to recommend. Journal of Travel Research, 56(1), 41-54. https://doi.org/10.1177/0047287515620567

Qeidari, H.S., Shayan, H., Solimani, Z., \& Ghorooneh, D. (2021). A phenomenological study of the learning experience of children in rural tourism destinations. Sage Journals 21(2), 235-259. https://doi.org/10.1177/1468797620985781

Sánchez-Fernández, M. D., Álvarez-Bassi, D., \& Ramón-Cardona, J. (2020). Management of Tourist Destinations: The Expectations of Guests on eWOM Generation in Maldonado (Uruguay). Sustainability, 12(17), 6825. https://doi.org/10.3390/su12176825

Shabala, L. P., \& Simatele, M. D. (2020). Perspectives on the identification and preservation of cultural heritage tourism products and services in South Africa: case study of Mapungubwe and Barberton Makhonjwa mountains world heritage sites. In Dominique Vanneste \& Wesley Gruijthuijsen (eds.) UNITWIN 8 Heritage Tourism (pp. 249-260).

Shaykh-Baygloo, R. (2021). Foreign tourists' experience: The tri-partite relationships among sense of place toward destination city, tourism attractions and tourists' overall satisfaction - Evidence from Shiraz, Iran. 
Baclig, E., \& Ylagan, A.

Journal of Destination Marketing \& Management, 19, 100518. https://doi.org/10.1016/j.jdmm.2020.100518

Sie, D. L., Pegg, D. S., \& Virginia Phelan, D. K. (2021). Senior tourists' self-determined motivations, tour preferences, memorable experiences and subjective well-being: An integrative hierarchical model. Journal of Hospitality and Tourism Management, 47, 237-251. https://doi.org/10.1016/j.jhtm.2021.03.006

Siedlecki, S. L. (2020). Understanding descriptive research designs and methods. https://doi.org/10.1097/NUR.0000000000000493

Stainton, H. (2021, October 18). Types of tourist attractions | Understanding tourism. https://tourismteacher.com/types-of-tourist-attractions/

Truyols, M. (n.d.). Gen Z travelers: how their travel behavior compares to millennial's. Hotelmize. https://www.hotelmize.com/blog/gen-z-travelers-how-their-travel-behavior-compares-to-millennials/

Universitat Pompeu Fabra - Barcelona. (2019, April 8). What most attracts us to a tourist destination? Attractions, culture and gastronomy. www.sciencedaily.com/releases/2019/04/190408114002.htm

Viola, R. (2019). Using new technologies to preserve the past. Digital Single Market. https://ec.europa.eu/digital-single-market/en/blogposts/using-new-technologies-preserve-past

Wang, T.-L., Tran, P. T. K., \& Tran, V. T. (2017). Destination perceived quality, tourist satisfaction and word-of-mouth. Tourism Review, 72(4), 392-410. https://doi.org/10.1108/tr-06-2017-0103

Wang, Y., Yang, Y., Huang, S. (Sam), Huang, L., \& Sun, W. (2021). Effects of air quality and weather conditions on Chinese tourists' emotional experience. Journal of Hospitality and Tourism Management, 48, 1-9. https://doi.org/10.1016/j.jhtm.2021.05.012

Wilson, D. L., Hallo, J. C., Sharp, J. L., Mainella, H. F. P., \& McGuire, F. A. (2017). Activity selection among baby boomer national park visitors: The search for a sense of adventure. Journal of Outdoor Recreation and Tourism, 19, 37-45. https://doi.org/10.1016/j.jort.2017.06.001

Yang, F. X., \& Lau, V. M.-C. (2019). Experiential learning for children at World Heritage Sites: The joint moderating effect of brand awareness and generation of Chinese family travelers. Tourism Management, 72, 1-11. https://doi.org/10.1016/j.tourman.2018.11.011

Yang, X., Wang, J., Sun, X., Zhang, H., Li, N., \& Liu, J. (2018). Tourism industry-driven changes in land use and ecological risk assessment at Jiuzhaigou UNESCO World Heritage Site. Journal of Spatial Science, 63(2), 341-358. https://doi.org/10.1080/14498596.2018.148512

Zhang, H., Wu, Y., \& Buhalis, D. (2018). A model of perceived image, memorable tourism experiences and revisit intention. Journal of Destination Marketing \& Management, 8, 326-336. https://doi.org/10.1016/j.jdmm.2017.06.004 